\title{
Textural Structure of Co-based Catalysts and their Performance for Fischer-Tropsch Synthesis
}

\author{
Jungang Wang • Debao Li • Bo Hou • \\ Litao Jia · Jiangang Chen $\cdot$ Yuhan Sun
}

Received: 21 May 2010/ Accepted: 9 September 2010/Published online: 24 September 2010

(c) The Author(s) 2010. This article is published with open access at Springerlink.com

\begin{abstract}
Both mono- and bi-modal Co-based FischerTropsch Synthesis (FTS) catalysts were prepared by incipient-wetness impregnation (IWI). XRD and $\mathrm{N}_{2}$ physisorption revealed that the catalyst with a bi-modal distribution of 2.5-17 nm had the smallest size of cobalt crystal. In this case, the Raman absorbance shifted toward lower frequencies due to the size quantization effect. Furthermore, $\mathrm{H}_{2}$-TPR indicated a lower reducibility originated from the interaction between small crystalline cobalt and silica. Such bi-modal structure catalysts showed a better FTS performance, and particularly the bi-modal mesopores catalyst presented the lowest methane selectivity, the highest activity and the highest selectivity to $\mathrm{C}_{5}-\mathrm{C}_{18}$ hydrocarbons, which might be due to the confinement of mesopore to the cobalt particles.
\end{abstract}

Keywords Cobalt catalyst - Pore size distribution · Fischer-Tropsch synthesis

J. Wang · D. Li $(\bowtie) \cdot$ B. Hou · L. Jia · J. Chen · Y. Sun

State Key Laboratory of Coal Conversion, Institute of Coal Chemistry, The Chinese Academy of Sciences, Taiyuan 030001, Shanxi, China

e-mail:dbli@sxicc.ac.cn

J. Wang

Graduate University of Chinese Academy of Sciences, Beijing 100049, China

\section{Y. Sun $(\square)$}

Low Carbon Conversion Center, Shanghai Advanced Research Institute, Chinese Academy of Sciences, Shanghai 201203, People's Republic of China

e-mail: yhsun@sxicc.ac.cn

\section{Introduction}

Fischer-Tropsch Synthesis (FTS), which is an alternative route for the production of diesel oil independent of petroleum material, has recently attracted much concern [1]. It is well known that supported cobalt catalysts are preferred for FTS because of their high activities and high selectivity to linear long chain hydrocarbons and also low activities for the competitive water-gas shift (WGS) reaction.

The performance of catalysts depends on many factors [2], such as preparation method, thermal treatment process, and the interaction between active species and support, catalyst compositions, metal dispersibility and types of inorganic supports used, etc. Thus, various materials were used as the supports of cobalt catalysts in past studies, including silica, alumina, kieselguhr, zeolite, titanium, carbon, and magnesia [3-7], which significantly influenced the reduction extent, the morphology, the adsorption capabilities and catalytic performance of the active phase, especially in well-dispersed catalytic systems. Among these supports, mesoporous silicas had attracted widespread attentions in FTS due to their high surface area, favoring the cobalt dispersion. Furthermore, the pore size could also control the cobalt particle size, improve the diffusion of reactants and products in the pore channel, and then influence the distributions of hydrocarbon products from the FTS.

Anderson et al. [8] reported that the FTS activity and selectivity of cobalt based catalyst could be affected by their pore sizes. And Xiong et al. [9] indicated that the pore size of alumina support could significantly influence the $\mathrm{Co}_{3} \mathrm{O}_{4}$ crystallite diameter, catalyst reducibility and FT activity. It was also reported [10] that the support with small pores could achieve a high dispersion of supported 
cobalt crystallites due to their high support surface area, and those supports with large pores could diminish the diffusion resistance and provide pathways for rapid molecular transport. Moreover, it was observed [11] that larger cobalt particles located in the wider pore silicas led to higher activity in FTS and lower methane selectivity than smaller cobalt particles situated in narrower pore supports.

Tsubaki et al. [12,13] prepared a bimodal catalyst with mesopores and macropores by introducing silica or zirconia sols into large-pore silica gel. Such a catalyst showed high activity and favorable selectivity owing to the high dispersibility of the cobalt crystallite in the bimodal structure. But the effects of bimodal regular mesopores and macropores on Co-based FTS catalysts remained not clear yet. Thus, in the present study, the catalysts with $15 \mathrm{wt} \%$ cobalt loading on supports with different pore size distributions were prepared by the same method, and the FTS over the catalysts were carried out to investigate the influence of mono-modal and bimodal structure.

\section{Experimental}

\subsection{Material Preparation}

\subsubsection{Support Preparation}

The mono-modal support was prepared by traditional method [11]. The bimodal mesopores and meso-macropores supports were prepared using CTAB as surfactant, but using $\mathrm{Na}_{2} \mathrm{SiO}_{3}$ and TEOS as silicon source, respectively.

SM-MCM41: In a typical synthesis, $1 \mathrm{~g}$ CTAB was dissolved in $480 \mathrm{ml}$ of distilled water. Afterwards $0.28 \mathrm{~g}$ $\mathrm{NaOH}$ was added, after the solution was stirred at $353 \mathrm{~K}$ for about $15 \mathrm{~min}, 5 \mathrm{ml}$ TEOS was added dropwise and the solution was continually stirring for $2 \mathrm{~h}$. The suspension was filtrated, dried in an oven at $333 \mathrm{~K}$ for $12 \mathrm{~h}$ and finally the sample was calcined at the rate of $5 \mathrm{~K} / \mathrm{min}$ to $823 \mathrm{~K}$ and hold for $6 \mathrm{~h}$. The obtained support was denoted as SM-MCM41(simple mesopores mono-modal MCM41).

MM-MCM41: The synthesis process of MM-MCM41 was similar to SM-MCM41. Under $353 \mathrm{~K}, 1 \mathrm{~g}$ CTAB was firstly dissolved in $480 \mathrm{ml}$ of distilled water, afterwards $16 \mathrm{ml} \mathrm{35 \%}$ ammonia was added. After stirring the solution for $15 \mathrm{~min}, 5 \mathrm{ml}$ TEOS was added dropwise. When the solution was continually stirred for another $2 \mathrm{~h}$, the suspension was filtrated, dried in an oven at $333 \mathrm{~K}$ for $12 \mathrm{~h}$, and finally the sample was calcined at the rate of $5 \mathrm{~K} / \mathrm{min}$ to $823 \mathrm{~K}$ and hold for $6 \mathrm{~h}$. The obtained support was denoted as MM-MCM41 (mesopores-marcopores bimodal mesopores).
DM-MCM41: In a typical synthesis, $19.6 \mathrm{~g}$ CTAB and $10 \mathrm{~g} \mathrm{Na}_{2} \mathrm{SiO}_{3}$ were dissolved in $350 \mathrm{ml}$ distilled water at $353 \mathrm{~K}$. After stirring for $30 \mathrm{~min}, 35 \mathrm{ml}$ ethyl acetate was added dropwise. Then the suspension was stilled for $5 \mathrm{~h}$, aged at $363 \mathrm{~K}$ for $48 \mathrm{~h}$. The suspension was filtrated, dried in an oven at $333 \mathrm{~K}$ for $12 \mathrm{~h}$, and finally the sample was calcined at the rate of $5 \mathrm{~K} / \mathrm{min}$ to $823 \mathrm{~K}$ and hold for $6 \mathrm{~h}$. The obtained support was denoted as DM-MCM41 (double mesopores bimodal mesopores).

\subsubsection{Catalyst Preparation}

The bimodal supported cobalt catalysts were prepared by incipient wetness impregnation (IWI) method using aqueous solution of cobalt nitrate as initial material. Firstly, the silicon supports were impregnated into the quantitative $\mathrm{Co}(\mathrm{N}-$ $\left.\mathrm{O}_{3}\right)_{2} \cdot 6 \mathrm{H}_{2} \mathrm{O}$ solution and stilled for $24 \mathrm{~h}$. Then, the samples were dried at $333 \mathrm{~K}$ for $12 \mathrm{~h}$. Finally, the cobalt-supported catalysts were obtained by calcining the above samples in air at $773 \mathrm{~K}$ for $2 \mathrm{~h}$. The synthesized Co/MCM41 catalysts with $15 \mathrm{wt} \%$ metal loading were denoted as Co/SM-MCM41, Co/DM-MCM41 and Co/MM-MCM41, respectively.

\subsection{Characterizations of Catalyst}

$B E T: \mathrm{N}_{2}$ adsorption-desorption experiment was conducted at $77 \mathrm{~K}$ with a ASAP-2000 Micromeritics instrument. Nitrogen isotherms were obtained in both adsorption and desorption modes. The surface areas of supports and catalysts were determined by the BET method. The total pore volume (TPV) was calculated from the amount of vapor adsorbed at a relative pressure $\left(\mathrm{P} / \mathrm{P}_{0}\right)$ close to unity, where $\mathrm{P}$ and $\mathrm{P}_{0}$ were the measured and equilibrium pressures, respectively. Pore size distribution curves were established from the desorption branches of the isotherm using the $\mathrm{BJH}$ model. Before the analysis, the samples were outgassed at $393 \mathrm{~K}$ for $12 \mathrm{~h}$.

$X R D$ : Rigaku D/max-RA instrument with $\mathrm{Cu}-\mathrm{K}$ radiation was used for the XRD measurement. The spectra were scanned at a rate of $2 \% \mathrm{~min}$ in the range $2 \theta=20-80^{\circ}$. The cobalt particle size $\left(\mathrm{Co}_{3} \mathrm{O}_{4}\right.$ at $\left.2 \theta=36.9^{\circ}\right)$ was calculated by using the full width at half maximum (FWHM) value with the help of Scherrer's equation as well.

Raman: Raman analysis was performed on a LABRAM-HR 800 spectroscopy at room temperature with an excitation wavelength of $514 \mathrm{~nm}$. A scanning range between 100 and $1000 \mathrm{~cm}^{-1}$ with a resolution of $2 \mathrm{~cm}^{-1}$ was applied.

TEM: The morphology of the samples was observed by transmission electron microscopy (TEM; Hitachi-600).

TPR: TPR experiments were carried out with a U-tube quartz microreactor heated by an electrical furnace to 
determine the reducibility of the catalyst sample. The reactor was loaded with $25 \mathrm{mg}$ catalyst and heated at a temperature ramp from 333 to $1233 \mathrm{~K}$ at $10 \mathrm{~K} / \mathrm{min}$ with a gas consisting of $5 \% \mathrm{H}_{2}$ in $\mathrm{N}_{2}$. The gas flow rate was $60 \mathrm{ml} / \mathrm{min}$. The $\mathrm{H}_{2}$ consumption (TCD signal) was recorded automatically by TCD detection.

\subsection{Catalyst Evaluation}

FTS reaction was performed in a fixed bed reactor (i.d. $=12 \mathrm{~mm}$ ) at $2.0 \mathrm{MPa}, 1000 \mathrm{~h}^{-1}$ and a $\mathrm{H}_{2} / \mathrm{CO}$ ratio of 2.0. The catalyst (60-80 mesh) was mixed with the same volume $\mathrm{SiO}_{2}$ to minimize the temperature gradient and reduced in a flow of hydrogen at $673 \mathrm{~K}$ for $6 \mathrm{~h}$ and then cooled down to ambient before switching to syngas. Data were taken at steady state after $24 \mathrm{~h}$ on-stream. The gas effluent was analyzed on a GC-920 chromatographs equipped with thermal conductivity detector (TCD) and flame ionization detector (FID). Liquid products and wax were collected in a cold trap and a hot trap, respectively, and were off-line analyzed on a GC-2010 chromatograph, which was equipped with a $35 \mathrm{~m}$ OV-101 capillary column.

\section{Results}

\subsection{Characterizations}

\subsubsection{Texture}

The isotherms of nitrogen adsorption and desorption, and the corresponding pore size distribution curves calculated using BJH method [1] of the catalysts were displayed in Figs. 1, 2, respectively. The isotherms of bimodal catalysts exhibited a typical irreversible IV type adsorption isotherm with two separate, well expressed H1 hysteresis loops at relative pressures $\mathrm{P} / \mathrm{P}_{0}$ of $0.2-0.4$ and $0.8-1$. The first

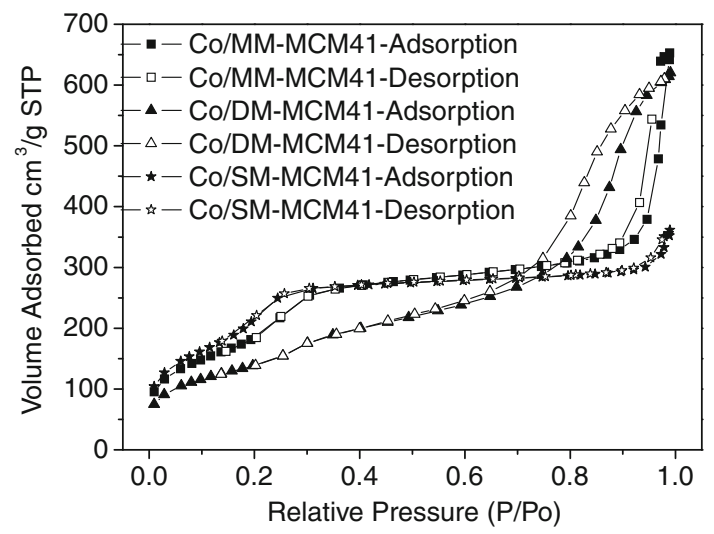

Fig. $1 \mathrm{~N}_{2}$ adsorption-desorption of catalysts

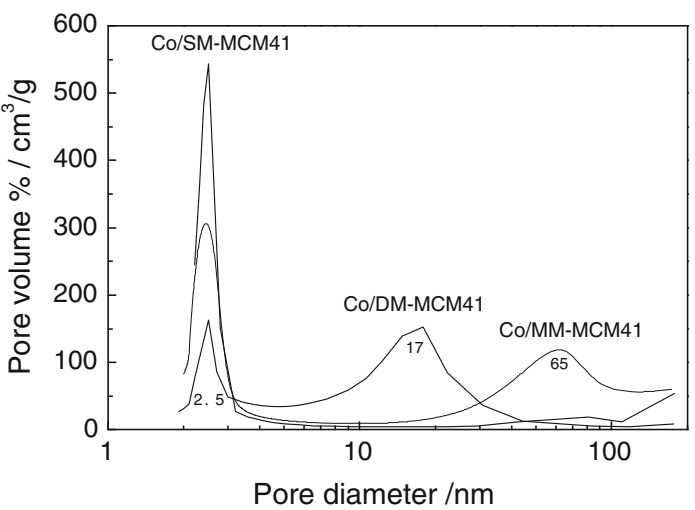

Fig. 2 Pore size distribution of the catalysts

condensation step on the isotherm at $0.2-0.4$ was similar to that for common MCM-41 materials with markedly higher saturation sorption capacity, though not very steep. The second condensation steps of the Co/DM-MCM41 and Co/MM-MCM41 on the isotherm at $\mathrm{P} / \mathrm{P}_{0}>0.8$ were steeper than the first ones and the hysteresis loops were more wide. This indicated the presence of a significant amount of secondary pore [14]. As shown in Fig. 2, it was clearly evident that there existed three kinds of pore, the maximum distribution centered at $2.5 \mathrm{~nm}$ for $\mathrm{Co} / \mathrm{SM}$ MCM41, 2.5, $17 \mathrm{~nm}$ for Co/DM-MCM41, and 2.5, $55 \mathrm{~nm}$ for $\mathrm{Co} / \mathrm{MM}-\mathrm{MCM} 41$, respectively.

The BET surface area, total pore volume and average pore diameter of the supports and corresponding catalysts were presented in Table 1. Compared with the respective supports, the cobalt loaded catalysts showed lower BET surface area, pore volume and smaller average pore size, but the pore size distribution has no obvious changes. The experimental BET surface area of Co/DM-MCM41 was $483 \mathrm{~m}^{2} / \mathrm{g}$, which was close to its theoretical data $\left(554 \mathrm{~m}^{2} /\right.$ g) [15], indicating that Co species might not block the pores, and a majority of cobalt species entered into the pore of support. This result was in agreement with the report [8] that cobalt species entered into the pore of support by incipient wetness impregnation method. Co/MM-MCM41 and Co/SM-MCM41 had the lower experimental surface areas than the theoretical data, and Co/DM-MCM41 had a slightly larger pore size than DM-MCM41, which might be due to the collapse of pore [15].

\subsubsection{Phase Structure}

The X-ray powder diffraction patterns of the catalysts were presented in Fig. 3, and the $\mathrm{Co}_{3} \mathrm{O}_{4}$ crystallite diameters, calculated by the Scherrer equation [16] $\left(2 \theta=36.9^{\circ}\right)$, were listed in Table 1. For all the catalysts, the diffraction peaks at $31.4^{\circ}, 36.9^{\circ}, 44.8^{\circ}, 59.4^{\circ}, 65.2^{\circ}$ were corresponding to the spinel $\mathrm{Co}_{3} \mathrm{O}_{4}$ phase. The size of $\mathrm{Co}_{3} \mathrm{O}_{4}$ crystallite changed from 12 to $34 \mathrm{~nm}$ for all the catalysts. 
Table 1 Physico-chemical properties of the supports and $\mathrm{Co} / \mathrm{SiO}_{2}$ catalysts

\begin{tabular}{lcllllll}
\hline Sample & $\mathrm{A}_{\mathrm{BET}} /\left(\mathrm{m}^{2} / \mathrm{g}\right)$ & $\mathrm{V} /\left(\mathrm{cm}^{3} / \mathrm{g}\right)$ & $\mathrm{d} /(\mathrm{nm})$ & Pore Size/(nm) & $\begin{array}{l}\mathrm{Co}_{3} \mathrm{O}_{4} \text { Crystalline } \\
\text { Size }(\mathrm{nm})^{\mathrm{a}}\end{array}$ & $\begin{array}{l}\text { Dispersion }(\%)^{\mathrm{b}} \\
\text { Reducibility }(\%)^{\mathrm{c}}\end{array}$ \\
\hline MM-MCM41 & $1177(1177)$ & 2.03 & 6.92 & $2.7,55$ & - & - & - \\
DM-MCM41 & $692(692)$ & 1.32 & 6.49 & $2.5,17$ & - & - & - \\
SM-MCM41 & $1126(1126)$ & 1.00 & 3.55 & $2.5, \infty$ & - & 4.25 & 8.00 \\
Co/MM-MCM41 & $673(942)$ & 1.01 & 5.99 & $2.5,65$ & 22.6 & 12.0 & 3.16 \\
Co/DM-MCM41 & $483(554)$ & 0.96 & 7.58 & $2.5,17$ & 30.4 & 78.83 \\
Co/SM-MCM41 & $738(901)$ & 0.56 & 2.81 & $2.5, \infty$ & & 72.11 \\
\hline
\end{tabular}

$A_{B E T}$ BET surface area (theoretical value), $d$ average pore diameter, $V$ pore volume

${ }^{\mathrm{a}}$ Obtained by Scherrer equation $d=\mathrm{k} \lambda / \cos \theta$; $^{\mathrm{b}}$ Calculated by: D $\%=96 / \mathrm{d}(\mathrm{nm}){ }^{(1)}$; ${ }^{\mathrm{c}}$ Calculated by TPR from 333 to $673 \mathrm{~K}$

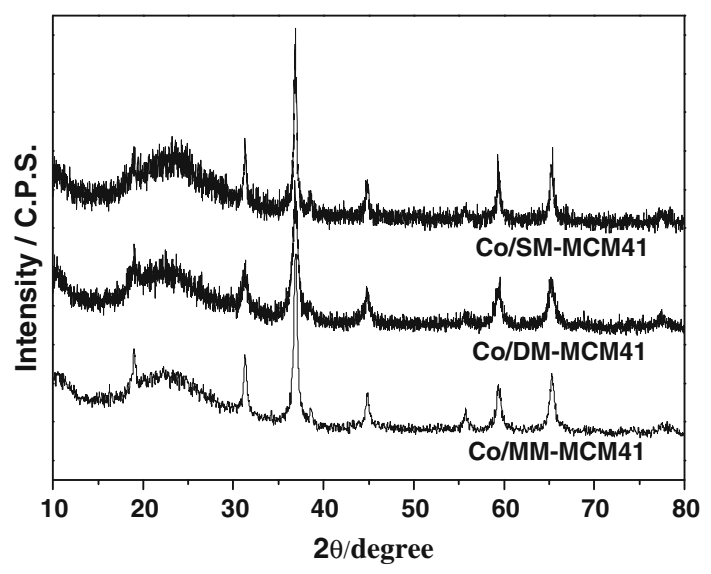

Fig. 3 XRD patterns of the Catalysts

Clearly, Co/DM-MCM41 had the smallest $\mathrm{Co}_{3} \mathrm{O}_{4}$ crystallite size $(12 \mathrm{~nm})$ in these samples. This result was not consistent with the literatures [1,13], which showed that the crystallite diameter increased with the pore size. $\mathrm{Co} / \mathrm{DM}-\mathrm{MCM} 41$ and $\mathrm{Co} / \mathrm{MM}-\mathrm{MCM} 41$ showed smaller $\mathrm{Co}_{3} \mathrm{O}_{4}$ crystallite sizes than the corresponding large pore size, implying that a majority of cobalt crystallites were located inside the pore and their growth was possibly confined by those pores. At the same time, Co/SM-MCM41 had the larger $\mathrm{Co}_{3} \mathrm{O}_{4}$ crystallites than the corresponding pore size, which indicated the cobalt species might mostly locate outside of the pores.

\subsubsection{Raman Spectroscopy}

Raman spectroscopy is a powerful tool in the study of the microstructure of nanoparticles [17]. It is known that $\mathrm{Co}^{2+}$ and $\mathrm{Co}^{3+}$ ions of $\mathrm{Co}_{3} \mathrm{O}_{4}$ oxide crystallizes with the normal spinel structure $\left(\mathrm{Co}^{2+}\left(\mathrm{Co}^{3+}\right)_{2}\left(\mathrm{O}^{2-}\right)_{4}\right)$ are located at tetrahedral and octahedral sites, respectively [18]. It has been known that the representative Raman peak positions of $\mathrm{Co}_{3} \mathrm{O}_{4}$ were $193,475,516,615$, and $680 \mathrm{~cm}^{-1}$, corresponding to all of the five Raman-active modes $\left(\mathrm{A}_{1 \mathrm{~g}}, \mathrm{E}_{\mathrm{g}}\right.$, and $3 \mathrm{~F}_{2 \mathrm{~g}}$ ) of $\mathrm{Co}_{3} \mathrm{O}_{4}$, respectively. Those absorbance, 672 ,
691, and $682 \mathrm{~cm}^{-1}$ corresponded to the $\mathrm{A}_{1 \mathrm{~g}}$ active mode of Co/DM-MCM41, Co/SM-MCM41 and Co/MM-MCM41, respectively (see Fig. 4a). Compared to Co/SM-MCM41, the Co/MM-MCM41 had a blue shift of about $9 \mathrm{~cm}^{-1}$ and Co/DM-MCM41 about $19 \mathrm{~cm}^{-1}$ due to the size quantization effect, i.e., the blue shift showed the decrease in the crystalline size. Thus, it could be concluded that the $\mathrm{Co}_{3} \mathrm{O}_{4}$ sizes reduced gradually in the order of Co/SM-MCM41, Co/MM-MCM41, and Co/DM-MCM41, which was coincident with the XRD result.

The post-catalysis Raman characterization was showed in Fig. 4b. After the reaction, those absorption peaks at 667, 672 , and $675 \mathrm{~cm}^{-1}$ corresponded to the $\mathrm{A}_{1 \mathrm{~g}}$ active mode of Co/DM-MCM41, Co/SM-MCM41, and Co/MM-MCM41, respectively. The Raman peaks indicated the existence of cobalt oxide in the post-catalysis. The above data showed the blue shift character of post-catalysis, which indicated the cobalt particles size decreased after reaction. This might be due to the reduction of cobalt oxide.

\subsubsection{TEM Micrographs}

Figure 5 showed TEM micrographs of three kinds of catalysts with different pore distribution. TEM investigation provides the direct observation of the morphology and distribution of Co particles in the support. The bimodal catalysts showed obvious pore structure of support, whereas the mono-modal catalyst blocked the pore, which indicated the cobalt particles located outside the pore in clusters. It was clearly displayed that the bimodal catalysts had smaller particle size and higher dispersion than that of mono-modal one. A close look at Co/DM-MCM41 revealed the presence of a considerable number of small cobalt clusters and more homogeneous cobalt distribution (see Figs. 5c, d), which almost existed in the two kinds of pore. The dark areas in the images of Figs. 5e, f showed that cobalt oxide clusters with a wide distribution concentrated more towards the external surface of the Co/SMMCM41 catalyst, which further confirmed the cobalt larger 
Fig. 4 Raman spectroscopy of the pre-catalysts and postcatalysts
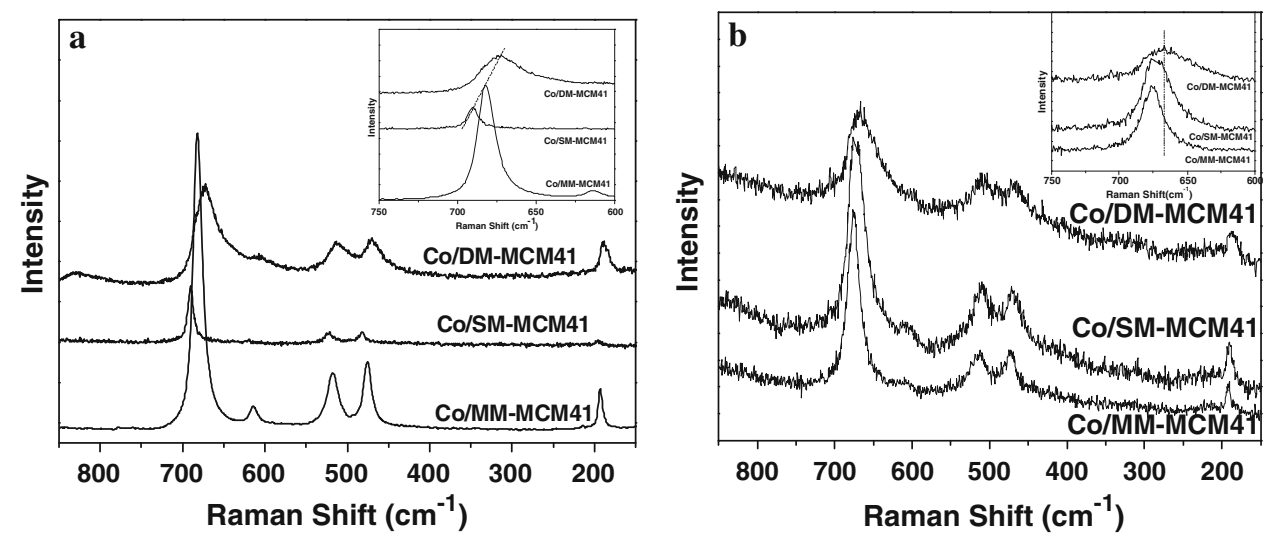
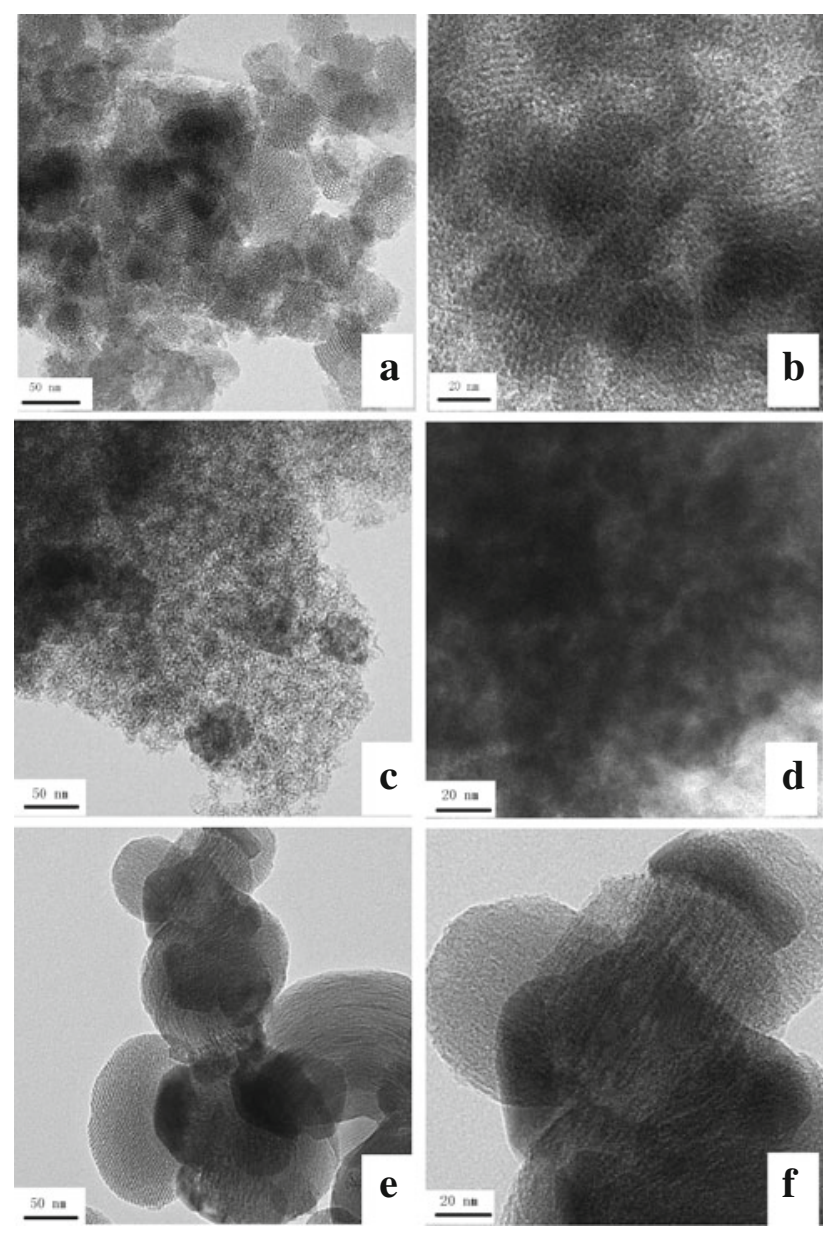

Fig. 5 The HRTEM images of catalysts. a, b Co/MM-MCM41; c, d $\mathrm{Co} / \mathrm{DM}-\mathrm{MCM} 41 ;$ e, f Co/SM-MCM41

cobalt particles existed outside the pore channel in agglomeration.

\subsection{Reduction Behavior}

TPR curves of the catalysts with different pore distribution were showed in Fig. 6 . The reduction process underwent

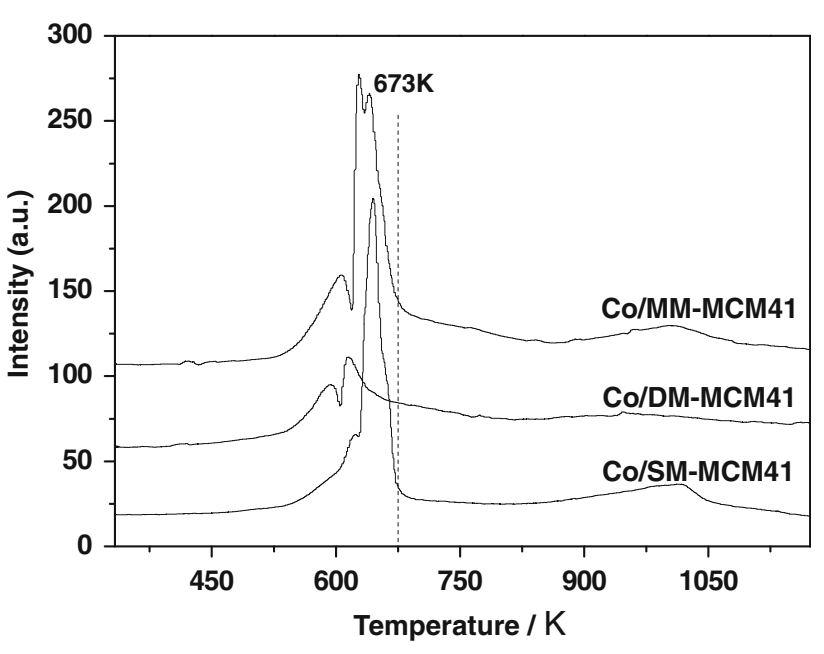

Fig. $6 \mathrm{H}_{2}$-TPR curves of the catalysts

three stages. This indicated the presence of several kinds of reducible cobalt species. The first reduction peak at 523-613 K could be attributed to the first reduction step of $\mathrm{Co}_{3} \mathrm{O}_{4}\left(\mathrm{Co}_{3} \mathrm{O}_{4} \rightarrow \mathrm{CoO}\right)$ [19], and the second reduction region at $613-673 \mathrm{~K}$ was due to the reduction of intermediate $\mathrm{CoO}$ phase $(\mathrm{CoO} \rightarrow \mathrm{Co})[1,20]$. These reduction peaks indicated that the cobalt oxides of all catalysts were reduced to metallic cobalt before $673 \mathrm{~K}$. However, for Co/MM-MCM41 and Co/SM-MCM41 catalysts, the high temperature reduction was observed at 923-1023 K, which might be caused by the presence of $\mathrm{Co}-\mathrm{Si}$ compound $\left(\mathrm{Co}_{2} \mathrm{SiO}_{3}\right)$ [21]. It should be mentioned that the second reduction region of Co/MM-MCM41 was comprised of more than one peak, which could be explained by the different cobalt particles size [22]. The literature reported that different size particles gave rise to varying the interaction between cobalt and support.

The reducibility of the catalysts were also calculated (see Table 1 ). The order of reducibility ranked as $\mathrm{Co} / \mathrm{SM}$ MCM41>Co/MM-MCM41>Co/DM-MCM41 (see Table 1). This was in agreement with the crystallite size of cobalt oxides, which was similar to those in the literatures $[11,23]$. 
Obviously, the large particles in wide pores were more easily reduced than small particles located in narrow pores.

\subsection{Catalytic Performance in FTS}

Table 2 and Fig. 7 show the activity and selectivity of catalyst in FTS. It should be noted that bimodal catalysts exhibited better catalytic activity than mono-modal one, especially the double mesopores catalyst with the pore size of 2.5 and $17 \mathrm{~nm}$. Such a structure not only led to the highest FTS catalytic activity but also the highest selectivity to $\mathrm{C}_{5^{-} 18}$ hydrocarbons (as high as about $62 \%$ ). Furthermore, the Co/DM-MCM41 catalyst presented the lowest methane selectivity, which was almost invariable with the increase of activity.

\section{Discussion}

The pore size was one of the key factors for the catalyst performance, and it affected the size of cobalt oxide particles, the mass transfer of reactants and products, the re-adsorption of $\alpha$-alkene, and the chemisorption ratio of $\mathrm{H}_{2}$ and $\mathrm{CO}$ on the surface active sites [4]. Table 2 and Fig. 7 showed the activity and selectivity of FTS catalysts were markedly depending on their pore structure. The cobalt particles size was also controlled by the pore size, and the relationship between cobalt nanoparticles size and FTS activity showed the obvious structure-sensitive character for FTS reaction, which was consistent with the literatures $[6,24]$. The bimodal catalysts had smaller cobalt particles and higher dispersion than that of mono-modal catalyst. Especially the double mesopores catalyst had the smallest particle size about $12 \mathrm{~nm}$ by the pore confinement. Compared to the mono-modal catalyst, the bimodal catalysts showed both higher $\mathrm{CO}$ conversion and $\mathrm{C}_{5}+$ selectivity, but lower methane selectivity.

For the Co/SM-MCM41 catalyst, its first pore size was only $2.5 \mathrm{~nm}$, but the size of cobalt particle was $30.4 \mathrm{~nm}$ as obtained by XRD. This indicated that only a small quantity of cobalt particles was located inside the smaller pore, and then the pore could not confine the growth of cobalt particles. It was well known that the reducibility increased
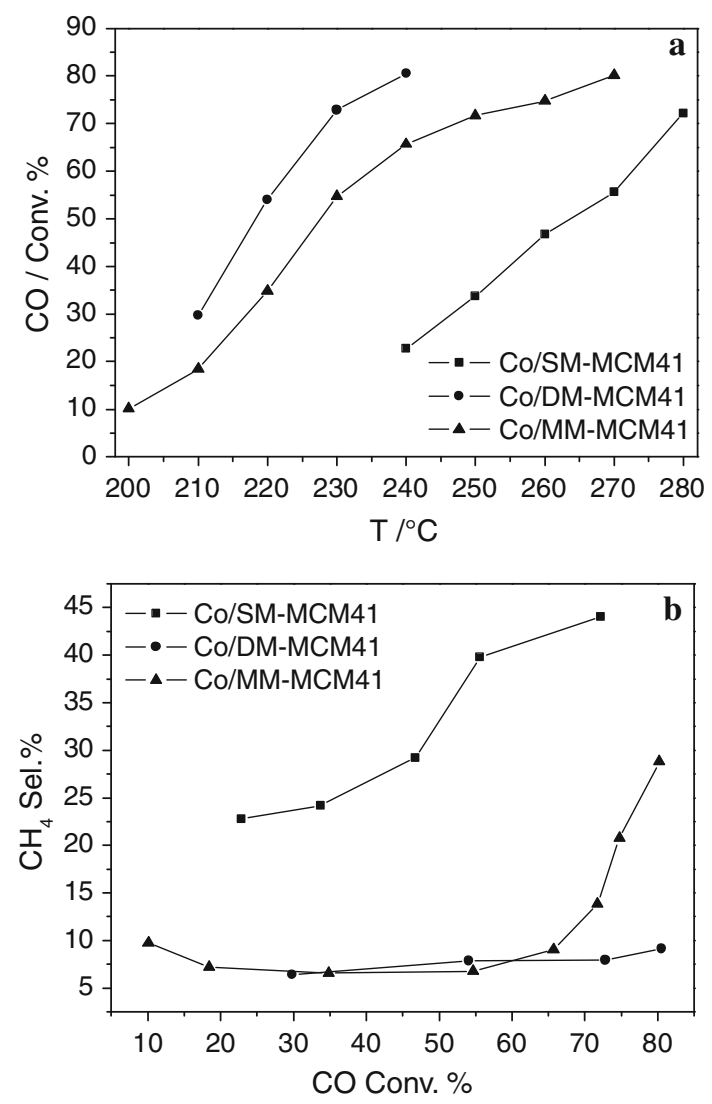

Fig. 7 Catalytic performances of the catalysts. a the relation of $\mathrm{CO}$ conversion and temperature; $\mathbf{b}$ the relation of $\mathrm{CO}$ conversion and $\mathrm{CH}_{4}$ selectivity

with the size of cobalt particles [8], so the Co/SM-MCM41 catalyst had the highest reducibility. However, the catalyst showed the lowest activity due to the formation of $\mathrm{Co}_{2} \mathrm{SiO}_{3}$ and the existence of less active sites on the cobalt species surface [25]. This was consist with the report [26] that larger concentration gradient existed in the larger cobalt particle interior, which caused the restriction of inner diffusion, decreased the diffusion and desorption ratios of $\mathrm{CO}$ and $\mathrm{H}_{2}$. As a result, the desorption of product within the cobalt particle was prevented, and the FTS activity and selectivity of the catalyst were affected.

For the bimodal catalyst, the $\mathrm{CO}$ conversion was greatly increased. Due to larger and smaller pores coexisting in the bimodal catalysts, their methane selectivity was

Table 2 Activity and selectivity of different catalysts for FTS

\begin{tabular}{|c|c|c|c|c|c|c|c|}
\hline \multirow[t]{2}{*}{ Catalyst } & \multirow{2}{*}{$\begin{array}{l}\mathrm{CO} \\
\text { Conversion }(\%)\end{array}$} & \multicolumn{6}{|c|}{ Selectivity (\%) } \\
\hline & & $\mathrm{CH}_{4}$ & $\mathrm{C}_{2-4}$ & $\mathrm{C}_{5+}$ & $\mathrm{C}_{5-11}$ & $\mathrm{C}_{12-18}$ & $\mathrm{C}_{19+}$ \\
\hline Co/SM-MCM41 & 22.81 & 22.81 & 13.84 & 63.35 & 28.83 & 25.93 & 8.59 \\
\hline Co/DM-MCM41 & 80.53 & 8.14 & 1.79 & 89.07 & 33.26 & 28.94 & 26.87 \\
\hline Co/MM-MCM41 & 65.69 & 9.03 & 5.67 & 85.30 & 25.99 & 29.95 & 29.36 \\
\hline
\end{tabular}

Reaction conditions $\mathrm{n}\left(\mathrm{H}_{2}\right) / \mathrm{n}(\mathrm{CO})=2.0$, GHSV $=1000 \mathrm{~h}^{-1}, \mathrm{p}=2.0 \mathrm{MPa}, \mathrm{T}=513 \mathrm{~K}$, stream on time: $112 \mathrm{~h}$ 
remarkably lower than that of mono-modal one, which was also proved by the literatures [22, 27, 28]. A catalyst having a small pore size tend to produce lighter hydrocarbons, and the larger pores can contribute to transport primary products,1-olefins, more effectively and to decrease the methane formation rate from secondary hydrocracking of olefins. For the Co/MM-MCM41 catalyst, both mesopores and macropores co-existed simultaneously. Little cobalt particles entered into the smaller pore, and a majority of cobalt particles were located in the macropores. In this case, the number of active sites increased, showing a higher FTS activity than Co/SMMCM41.

Due to the double mesopores coexisting, the Co/DMMCM41 catalyst not only had the highest FTS activity and $\mathrm{C}_{5}+$ selectivity, but also the lowest methane selectivity in three kinds of catalysts. Although the activity of Co/DMMCM41 catalyst was highest, the reducibility obtained from TPR was lowest, the result was not consistant with the result [23]. This could be due to the pore distribution and confinement of cobalt particles by the second mesopores of $17 \mathrm{~nm}$, which has been proved by the XRD, Raman and TEM. This resulted in a higher dispersion of cobalt species [20] (see Fig. 5) and formation of more active sites formed, so the Co/DM-MCM41 catalyst showed the highest FTS activity. Furthermore, the Co/DM-MCM41 catalyst had the lowest methane selectivity and higher middle distillate selectivity than other two catalysts. This was similar to the literatures [1,29], which was due to the co-existence of large and small pores in bimodal support. Sun et al. [4] also reported that there were different chemisorption ratios of $\mathrm{H}_{2}$ and $\mathrm{CO}$ on the surface active sites for the catalysts with different pore size. The large molecules in the product could not get out of the appropriate pore, favoring to produce lighter hydrocarbons [23]. Consequently, the Co/DMMCM41 catalyst showed a higher selectivity to the middle distillates.

\section{Conclusion}

Both mono- and bi-modal cobalt-based FT catalysts were prepared by incipient-wetness impregnation method. The results showed that the bimodal structure catalysts present higher $\mathrm{CO}$ conversion and $\mathrm{C}_{5}+$ selectivity, lower methane selectivity than mono-modal catalyst. This might be because the bimodal mesoporous structure strongly influenced the cobalt crystallite size, the dispersion, the reducibility and the FT catalytic performance. Amongst them, the bi-modal catalyst with $2.5-17 \mathrm{~nm}$ pores showed the high activity, the low selectivity to methane and the high selectivity to middle distillates due to the confinement effect of the bimodal mesoporous structure.
Acknowledgments This work was supported by the Natural Science Foundation of China (Contract No. 20590361, 21076218 and 21003149).

Open Access This article is distributed under the terms of the Creative Commons Attribution Noncommercial License which permits any noncommercial use, distribution, and reproduction in any medium, provided the original author(s) and source are credited.

\section{References}

1. Khodakov AY, Constant AG, Bechara R, Zholobenko VL (2002) J Catal 206:230

2. Chu W, Hong JP, Payen E, Dai XY (2007) Chin J Chem Phys 20:743

3. Jongsomjit B, Panpranot J, Goodwin JG Jr (2003) J Catal 215:66

4. Liu YC, Fang KG, Chen JG, Sun YH (2007) Green Chem 9:611

5. Jongsomjit B, Wongsalee T, Praserthdam P (2006) Mater Chem Phys 97:343

6. Bezemer GL, Bitter JH, Kuipers HPCE, Oosterbeek H, Holewijn JE, Xu XD, Kapteijn F, Dillen AJV, Jong KP (2006) J Am Chem Soc $128: 3956$

7. Zhang JL, Chen JG, Ren J, Sun YH (2003) Appl Catal A: Gen 243:121

8. Xiong HF, Zhang YH, Liew KY, Li JL (2008) J Mol Catal A: Chem 295:68

9. Song DC, Li JL (2006) J Mol Catal A: Chem 247:206

10. Li HL, Li JL, Ni HK, Song DC (2006) Catal Lett 110:71

11. Khodakov AY, Bechara R, Griboval-Constant A (2003) Appl Catal A: Gen 254:273

12. Zhang Y, Yoneyama Y, Fujimoto K, Tsubaki N (2003) Top Catal 26:129

13. Zhang Y, Koike M, Yang RQ, Hinchiranan S, Vitidsant T, Tsubaki N (2005) Appl Catal A: Gen 292:252

14. Barrera A, Muramatsu K, Viveros T, Gomez S, Montoya JA, Angel PD (2009) Appl Clay Sci 42:415

15. Yang WS, Fang DY, Xiang HW, Li YW, Li JS (2005) Chin J Catal 26:329

16. Cullity BD,(1978),Elements of X-Ray Diffraction(2nd ed)

17. Xu CY, Zhang PX, Yan L (2001) J Raman Spectrosc 32:862

18. Zhou HJ, Chen LM, Malik V, Knies C, Hofmann DM (2007) Physica Status Solidi a-Appl Mater Sci 204:112

19. Steen Ev, Sewell GS, Makhothe RA, Micklethwaite C, Manstein H, Lange MD, O'Connor CT (1996) J Catal 162:220

20. Girardon JS, Quinet E, Griboval-Constant A, Chernavskii PA, Gengembre L, Khodakov AY (2007) J Catal 248:143

21. Kogelbauer A, Weber JC, Goodwin JG (1995) Catal Lett 34:259

22. Zhang Y, Koike M, Yang RQ, Hinchiranan S, Vitidsant T, Tsubaki N (2005) Appl Catal A-Gen 292:252

23. Borg O, Hammer N, Eri S, Lindvag OA, Myrstad R, Blekkan EA, Ronning M, Rytter E, Holmen A (2009) Catal Today 142:70

24. den Breejen JP, Radstake PB, Bezemer GL, Bitter JH, Froseth V, Holmen A, de Jong KP (2009) J Am Chem Soc 131:7197

25. Yamamoto Y, Hatanaka S, Tsuji K, Tsuneyama K, Ohnishi R, Imai H, Kamiya Y, Okuhara T (2008) Appl Catal A:Gen 344:55

26. Ji YG, Zhao Z, Yu CC, Duan AJ, Jiang GY (2007) Chem Ind Eng Prog 26:927

27. Zhang Y, Nagamori S, Yamaguchi M, Rengakuji S, Tsubaki N (2008) Catal Commun 9:902

28. Zhang Y, Shinoda M, Tsubaki N (2004) Catal Today 93-95:55

29. Job N, Pereira MFR, Lambert S, Cabiac A, Delahay G, Colomer JF, Marien J, Figueiredo JL, Pirard JP (2006) J Catal 240:160 